\title{
Preface
}

\author{
Christopher M. A. Brett*
}

\section{Pure and Applied Chemistry Diamond Jubilee Issue}

https://doi.org/10.1515/pac-2020-1106

Keywords: Diamond Jubilee Issue; IUPAC Prize for Young Chemists; IUPAC-Solvay International Award for Young Chemists.

This issue of Pure and Applied Chemistry celebrates its 60th Anniversary, its Diamond Jubilee. It brings together articles on diverse themes by 12 scientists, winners of the IUPAC-Solvay International Award for Young Chemists and the IUPAC Prize for Young Chemists during the last decade since 2011, the International Year of Chemistry, and makes a fitting tribute to the journal on its 60th anniversary.

The journal Pure and Applied Chemistry started life in 1960 as the scientific journal of the International Union of Pure and Applied Chemistry (IUPAC) in order to publish reports and papers from its commissions, sections and divisions in a systematic and unified way [1]. The aim was to make this information available to the worldwide scientific community and not just in the chemistry publications of member countries, who played a crucial and significant role, but were unable to make all the papers and recommendations available. Proceedings of scientific conferences were also included.

Since then Pure and Applied Chemistry has grown in size and in breadth for several reasons, but its basic structure has remained the same reflecting the excellent choices made at the journal's inception. First, the work being carried out by IUPAC's volunteer scientists in promoting a common language in and understanding of the concepts of chemistry through recommendations and technical reports that are published in $P A C$, all of which are open access, as well as in the well-known series of colour books. Secondly, selected articles based on presentations made in IUPAC-endorsed conferences which have increased in number and contain the latest state-of-the-art advances in the topics of the conferences and are written by world experts. Thirdly, special issues which have a specific theme [2] or are winners of awards, such as this special issue.

The world currently faces many challenges that include health, foods and the environment, and included in the United Nations Sustainable Development Goals in the 2030 Agenda. Chemistry plays an important part of the solution to many of these challenges, and research in fundamental science underpins the development of the science and technology needed for all such applications. Recognising and rewarding early career researchers is an important way of furthering this aim. That is why, since 2000, IUPAC has awarded annual prizes for the most outstanding Ph.D. theses in the area of the chemical sciences, based on detailed analysis of a 1000-word essay on the candidate's research by the prize selection committee. IUPAC is very pleased that in 2014, Solvay joined this initiative to establish the IUPAC-Solvay International Award for Young Chemists [3].

Article note: The call for application for the IUPAC-Solvay International Award for Young Chemists is coordinated yearly; the next deadline is 15 Feb 2021 for candidates having completed their Ph.D. during calendar 2020; https://iupac.org/2021-iupac-solvayinternational-award-for-young-chemists/

*Corresponding author: Christopher M. A. Brett, President, International Union of Pure and Applied Chemistry, Department of Chemistry, University of Coimbra, 3004-535 Coimbra, Portugal, e-mail: cbrett@iupac.org 
The last issue of PAC linked to a celebration of the success of these awards was on the occasion of the International Year of Chemistry in 2011 and contained a rich selection of excellent papers by winners of the award during its first 10 years [4].

This special issue continues this aim and the titles of the 12 manuscripts from winners between 2011 and 2019 show the diversity of research that is covered. They are on topics which are at the forefront of current research and represent the state of the art. Themes that are covered in the articles are linked to the harnessing of solar energy through photoredox catalysis and artificial photosynthesis, solar fuel production and photovoltaics, to controlling and growing structures at the nanoscale. The industrial viability of processes for capturing carbon dioxide and to new catalysts are addressed. Contributions also concern strategies for successfully initiating enthusiastic students into a research environment and career, which is necessary for future sustainability in scientific and chemistry research. The articles bridge two or more of these key topics mentioned above and show, at the same time, how important interdisciplinarity is, but that chemistry is central to addressing these questions.

I am sure that you will enjoy reading this special issue and that it will help to promote new ideas and thinking. Congratulations to $P A C$ !

Christopher Brett

IUPAC President

\section{References}

[1] H. W. Thompson. Pure Appl. Chem. 1, 3-4 (1960).

[2] D. Fauque, J. Bull. Chem. Int. 42, 12-15 (2020).

[3] M. Cesa, N. Tarasova, P. Baekelmans. IUPAC-Solvay International Award for Young Chemists 2000-2019: A Retrospective. IUPAC 100 Stories, Retrieved from https://iupac.org/100/stories/iupac-solvay-international-award-for-young-chemists-20002019/ (accessed Nov 2, 2020).

[4] N. Moreau. Pure Appl. Chem. 83, iv (2011). 